\title{
When the means do not justify the end
}

\author{
Sudden Origins: Fossils, Genes, and \\ the Emergence of Species \\ by Jeffrey H. Schwartz \\ Wiley: 1999. 408 pp. $119.99, \$ 27.95$

\section{Eörs Szathmáry}

The origin of species has long fascinated biologists. Although Darwin's major work bears it as a title, it does not provide a solution to the problem. Does Jeffrey Schwartz give one? I am afraid that, in general, he does not, but the book is still interesting.

Schwartz presents a detailed and informative historical account of evolutionary biology. In fact, the book could be read as a history of evolution, and will probably occupy such a niche. Schwartz is much more ambitious than this, however: he wants to convince the reader that his "new evolution" is the Holy Grail of the field.

These are the elements of his proposal. First, forces of speciation are largely independent of selection within the species. Second, speciation is typically triggered by a mutation in a homeobox gene. Third, such a mutation is likely to become fixed in population isolates. Fourth, the mutation remains unnoticed for a long time because of its recessive nature. Fifth, when it reaches homozygosity in the small isolate, it will appear in several individuals simultaneously. Sixth, the mutation, since it affects development, is likely to affect mate choice as well; hence, mutant homozygotes are likely to mate among themselves.

Although Schwartz has in one sense resurrected Richard Goldschmidt's "hopeful monsters" (organisms with radically altered characteristics, produced in single large steps), he thinks that he has managed to avoid the associated pitfalls. The homeobox mutations would be macromutations in their effects, but from the genetic point of view they would qualify as micromutations, since no large genomic rearrangements are implied. The problems of finding a mate also seem to be solved by the dynamics of recessives (mutant homozygotes are thought to appear simultaneously, following a lag phase of heterozygosity). And, since homozygosity and preferential mating (pre-zygotic isolation) go hand in hand, there would be no transitional forms.

A drawback of this scenario is the absence of a population-genetic treatment. One is therefore left uncertain about the effects of population size, fixation time, and so on. It is not even certain whether Schwartz thinks that the mutant homozygotes have a selective advantage or are effectively neutral for the individual. In the latter case, the logic of the scenario still suggests that they would influence the dynamics of sexual selection,

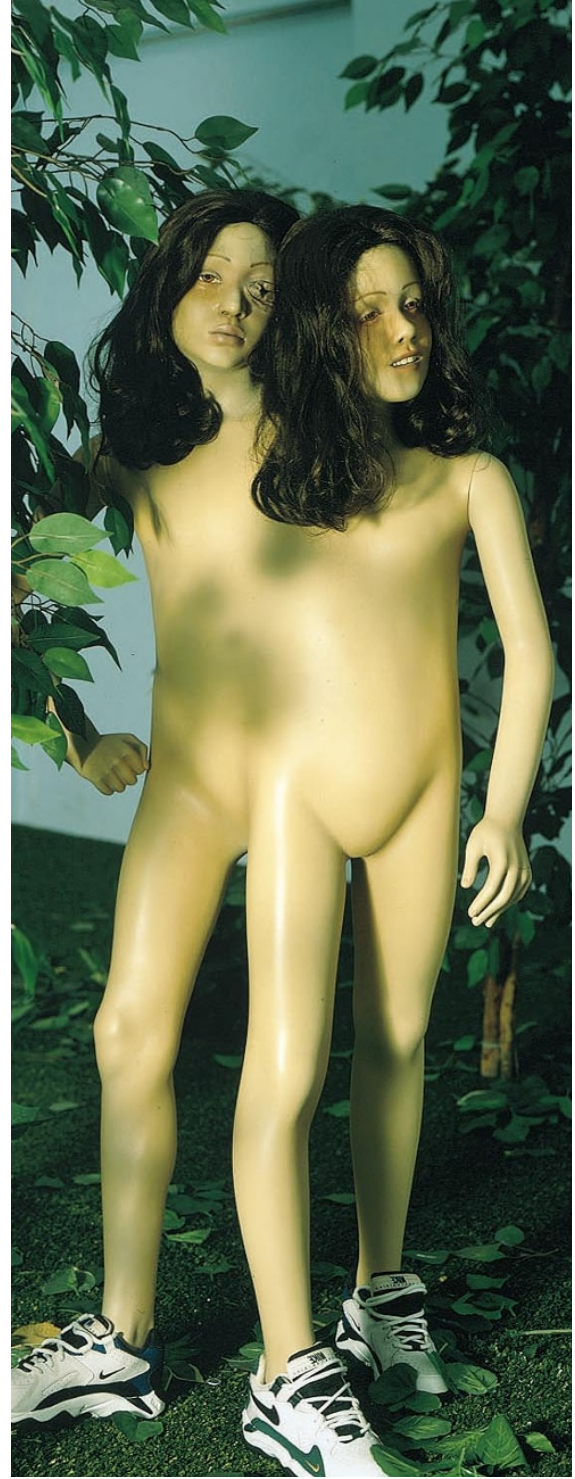

Evolution by radical mutation: "Tragic anatomies" by Jake and Dinos Chapman.

an interesting possibility. There is nothing wrong with dreaming up a verbal evolutionary scenario, but these days this surely cannot be the last word.

Another shortcoming of the book is the lack of at least one documented case of speciation that may have happened following Schwartz's scenario. Examples that could be taken as evidence for the component processes are discussed in some detail, but this does not rule out the possibility that one case that fits the complete scenario would never be found.

Schwartz shares a distrust of selection with some contemporary biologists. This is, I think, why he chose to ignore, for example, Peter Sheldon's work on the gradualism apparent in the evolution of the pygidial ribs of trilobites. When he discusses the celebrated computer study by Dan Nilsson and
Susanne Pelger on the evolution of the optical structure of a fish eye, he mistakenly suggests that the intermediates are not selective improvements on the previous forms. It is revealing that he dismisses this scenario by saying: "Do we actually need to invoke such an elaborate thought experiment in order to understand the origin of the vertebrate eye, or any eye, for that matter? I think not. And the reasons lie in knowing that there are homeobox genes for eye formation and that when one of them, the $R x$ gene in particular, is activated in the right place and at the right time, an individual has an eye."

This is utterly misleading. Schwartz ignores the fact that homeobox genes are selector genes. They can do nothing if the genes regulated by them are not there. It is these genes that specify in detail the adaptive structure of the organs. To be sure, turning on a homeobox gene at the wrong place can result in the appearance of an ectopic organ, but only if the genes for that organ are present in the same individual. It is totally wrong to imply that an eye could be produced by a macromutation when no eye was ever present in the lineage before. Homeotic mutations that reshuffle parts do happen, and sometimes they may have led to fixation of real evolutionary novelties, but this does not mean that such changes are implied in the majority of speciations. In fact, macromutations of this sort are probably frequently maladaptive, in contrast to the vast number of past and present species - not to mention the fact that morphological differences between related species can be minute.

The history given in the book is fascinating, and some of the suggestions merit further work, but the reader is likely to be deeply disappointed more than once before the end.

Eörs Szathmáry is at the Collegium Budapest, Szentháromság u2, H-1014 Budapest, Hungary.

\section{This passion of our kind}

\section{La Galassia Mente}

by Rita Levi Montalcini

Baldini \& Castoldi: 1999. 218 pp. Lire 29,000

\section{Lucia Galli-Resta}

The Galaxy of the Mind aims to stimulate reflection on the complexity of the human brain. At a time when biotechnology has such a powerful impact on our lives and expectations, in a country where scientific education has still to be 'perfected', this book has its small, valuable place. The book has a simple and important message: our mind, 
about which we still know so little, is our master and our slave. The values we foster in our culture and in our children will ultimately decide whether the mind serves knowledge or intolerance, and how it will guide mankind in the use of knowledge.

Rita Levi Montalcini begins by tracing a succinct picture of the evolutionary origins of the nervous system, delineating its principal unitary characteristics as well as its diversification. Her description culminates with Lucy: " 52 bones ... of the skeleton of a single individual, a female hominid ... with a skull not larger than a coconut". Here, halfway through the book, I switched off the light and went to sleep. In the dark of the night I wondered whether angst moved in her brain and whether she, as W. H. Auden once wrote, "our own shrew ancestor, was Nobody, but still could take herself for granted".

Resuming the next day, I met the "human brain' in the lively metaphor of a game of chess - neocortex as king; lymbic system as queen; and the subcortical regions as their bishops, castles and knights. Last but not least, the pawns: lymphokines, growth factors, enkephalins, and so on. In the most difficult chapters of the book, language, thought, mind and consciousness are all briefly considered in a summary of views which one might or might not share, but which still convey the vividness of the debate, and how far we are from a solution.

The author has the merit of rarely taking sides, doing so mostly through the verses chosen to introduce each chapter. Although reading these chapters may be somewhat laborious, the book rushes on. On the subjects of free will and emotions, the author's charm mitigates the reader's frustration at the brief treatment of the subjects, and leaves us with two images. The first is a dog roaming at the end of a long leash, to suggest the interplay - limited yet vital - between what we call our freedom of thought and our biological constraints. The second image is a little warning, showing the folded mantel of the neocortex wrapping, but not trapping, a primordial reptilian brain, as powerful in giving us emotions as it is fearsome in its obscure potentialities.

The finale, which is prefigured by a word appearing often in the text - ethic — is a simple message of great relevance: science has revealed new and unpredictable horizons to mankind; the choice is between good and evil. As Levi Montalcini says: "The bond between science and morality must be strengthened."

To return to Auden, "this passion of our kind/ for the process of finding out/ is a fact one can hardly doubt". Levi Montalcini's book suggests a healthy diet to feed this passion: "science allows an unambiguous language, understandable by the most different nations ... Promoting a friendship based on the exchange of knowledge and reciprocal contacts may be the most important contribution of science and technology to humankind."

One may like or dislike this little book aimed at a popular audience, but the message — from a great scientist, and a woman who is a living embodiment of the passion for knowledge - should not be ignored.

Lucia Galli-Resta is at the Istituto di

Neurofisiologia del CNR, via San Zeno 51, 56127 Pisa, Italy.

\section{Ditties of the fragile and the inscrutable}

\section{Musical Networks: Parallel Distributed Perception and Performance}

edited by Niall Griffith and Peter M. Todd MIT Press: 1999.385 pp. \$37.50, £26.50

\section{Christopher Longuet-Higgins}

From time to time, a previously dormant subject suddenly comes to life and challenges our preconceptions about its concepts and methods. A quarter of a century ago this happened to music theory, when people realized that the perception and performance of music are psychological processes that might be amenable to computational modelling.

A good start was made in applying the concepts of artificial intelligence to music psychology, but this was soon eclipsed by the connectionist paradigm - the doctrine that, since the brain is a parallel distributed processor or, as some would say, an adaptive neural network, all statements about music should be reducible to statements about the activity of such networks.

Sidney Brenner, one of the founders of molecular biology, once remarked that a mature science was one in which the number of competing theories was equal to one. On that criterion, music psychology is still in its

infancy. There is fierce competition, not only between theories, but between types of theory - between fragile artificial-intelligence models and inscrutable neural networks. The AI models seem more successful at capturing the role of knowledge in musical cognition, the neural-net models at explaining the acquisition of perceptual skills.

Musical Networks testifies to the breadth of influence that connectionism has exerted on the psychology of music, or at least on its literature. Many of the chapters were originally published in a symposium entitled Music and Creativity (edited by Griffith and Todd and published in a special issue of Connection Science, Vol. 6, parts $2 \& 3$; 1994), but here we find connectionist accounts of processes as wide-ranging as pitch perception, key identification, rhythmic entrainment, voice separation, metre induction and even the use of Boltzmann machines in the harmonization of chorales. One is reminded of the creativity test, "How many uses can you think of for a brick?". Unfortunately, the non-specialist is left in no position to judge which of the many networks proposed are realized in the central nervous system and which are not.

A topic conspicuous by its absence from Musical Networks is musical grammar. There are two likely reasons for this. One is a suspicion that the topic might have been preempted (actually it wasn't) by Fred Lerdahl and Ray Jackendoff's A Generative Theory of Tonal Music(MIT Press), an attempt to do for music what Noam Chomsky did for language. The other is the connectionist's allergy to replacement rules and other top-down procedures for arriving at well-formed strings, sequences, sentences and phrases. The great attraction of connectionism is that it seems to solve the problem of teaching a system new tricks: let it pick them up for itself. The snag is, of course, that the learning process may be impossible to understand. For practical purposes, such as music

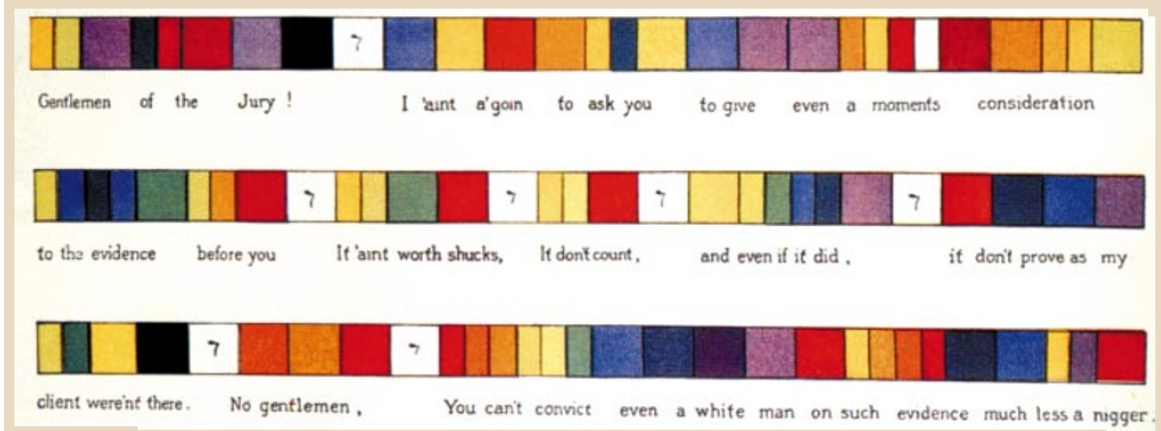

\section{A sight of sound}

“Lawyer Spoke Stith's address to the jury" (1900) might be a colourful representation of synaesthesia. Shown above is a visualization of the colours of his spoken words by the American architect and designer E. J. Lind, who formulated such ideas in the 1880s. Taken from Colour and Meaning: Art, Science and Symbolism by John Gage (Thames \& Hudson, $\mathfrak{E 3 2}$ ). 